OPEN ACCESS

Edited by:

Milton D. Cox

Miami University, United States

Reviewed by:

Adamantios Koumpis,

University of Passau, Germany

Adrian Sin Loy Loh,

National Junior College, Singapore

*Correspondence:

Siu Yin Cheung

cheungsy@hkbu.edu.hk

Specialty section: This article was submitted to

Digital Learning Innovations,

a section of the journal

Frontiers in Education

Received: 30 October 2020 Accepted: 01 March 2021

Published: 31 March 2021

Citation:

Cheung SY and Ng KY (2021) Application of the Educational Game

to Enhance Student Learning.

Front. Educ. 6:623793.

doi: $10.3389 /$ feduc. 2021.623793

\section{Application of the Educational Game to Enhance Student Learning}

\author{
Siu Yin Cheung* and Kai Yin Ng \\ Department of Sport, Physical Education and Health, Hong Kong Baptist University, Kowloon, Hong Kong
}

The purpose of this study is to investigate the use of an educational game to enhance student learning effectiveness. This study consisted of 56 college students majoring in physical education and recreation management (32 men, 24 women, age $M=21$ years, $S D=1.72$ ). Students used the educational computer game "PaGamO" to study the motor learning and development course. Students received rewards based on their individual and group "PaGamO" scores. Regression analysis indicated that "PaGamO" score was a significant $(\rho<0.01)$ predictor of multiple choice $(\mathrm{MC})$ score in the final examination, there was a medium positive correlation $(\beta=0.354)$. The $R^{2}$ suggests that $12.6 \%$ of MC score was explained by "PaGamO" score. Quantitative and qualitative mixed-method approach was used to gain insights into students' perceptions and experiences of the educational game. The top three statements of a modified questionnaire from Riemer and Schrader (2015) are: (1) "In my opinion, the use of 'PaGamO' enables me to better prepare for the final examination" ( $M=5.04, S D=1.41)$, (2) "In my opinion, the use of 'PaGamO' enables me to understand learning contents" $(M=4.8, S D=1.19)$, (3) "In my opinion, the use of 'PaGamO' allows me to apply knowledge" ( $M=4.75, S D=1.08)$. The top three motives to play "PaGamO" were "fun," "self-learning," and "want to get a higher grade in the final examination." By using gamification as a tool for learning and studying, students did find "PaGamO" effective for their learning experience. Both intrinsic and extrinsic participation motives are reasons why students play "PaGamO." Furthermore, due to its convenience, using mobile devices to play "PaGamO" is more popular than using computers and tablet devices. In conclusion, the combination of gamification and traditional learning methods can enhance students' learning outcomes.

Keywords: educational game, learning, self-determinated motivation, intrinsic motivation, perceptions

\section{INTRODUCTION}

Gamification in education has become the focus of attention in recent years. While "gamification is the practice of using game design elements, game mechanics and game thinking in non-game activities to motivate participants" (Al-Azawi et al., 2016, p. 133), educational gamification is a teaching method that requires learners to participate in competitions according to preset rules (Fitzgerald, 1997). It has been an interdisciplinary and prevalent tool for educators to utilize in teaching in the past few years (Robson et al., 2016). In view of the rapid development of technology, learners may expect teachers/lecturers to employ this tool in lessons/lectures (Rondon et al., 2013). In the field of education, researchers have been eager to find new strategies to enrich students' 
learning experiences, especially in this technology-driven world in which educational games are one of them (Minovic et al., 2012a).

\section{Effectiveness of Educational Games}

A systematic literature review had been conducted by Calderón and Ruiz (2015) who found that 53 educational games research literature had adopted different methods to assess the effectiveness of diverse educational games in the period between November 2013 and April 2015, compared to 18 and 20 games used in health and wellness, and the professional learning and training domain, respectively. They also reported that $60 \%$ of these 53 studies examined the effectiveness of using educational games in higher education setting, compared to only $40 \%$ in primary or secondary school settings, indicating that teachers in higher education are more likely to combine educational games with traditional teaching methods into students' learning experiences-a sign of creativity of embracing the new strategy to enrich students' learning experience.

Gamification has become popular in education in recent years. Its advantages include, but not limited to, giving students the opportunity to experience learning in a multi-sensory, active and experimental environment. Specifically, learners can use these educational games for experimental learning to develop their decision-making and problem-solving skills in a dynamic learning environment (Adachi and Willoughby, 2013). In addition, students can receive feedback/results immediately to get answers, instead of receiving delayed feedback from traditional assessment methods (e.g., tests and examinations). Moreover, some educational gamification may help to reduce limitations, including time and place, as portable devices can enable students to study and/or learn anytime and anywhere. These user-friendly tools can make difficult subjects easier to understand and memorize (Hanus and Fox, 2015). In other words, with the use of educational games, the learning process is considered to be more interesting (Calliari, 1991), motivating (Sun-Lin and Chiou, 2019), achieving knowledge retention (Gros, 2007), increasing attention (Prensky, 2003), and can even enhance peer communication and social skills (Liao et al., 2011).

Although extensive research supports the use of educational games to help improve students' learning experience, it has been found that young students are more likely to be inattentive (Wickens, 1974), and the use of educational games, among the many other solutions, to alleviate the issue may become helpful. Research shows that students' attitudes toward learning, class attendance and mood were more positive when compared to primarily using traditional methods of teaching and learning (Vernon and Blake, 1993). It is believed that in the learning process, when students have the opportunity to participate in decision-making, they are more likely to enjoy learning because they regard "learning" as "playing" (Zapalska et al., 2012). Even though as children grow older, their attention and concentration may correspondingly increase (Wickens, 1974), it is important to ensure that students' learning motivation can remain at a high level. In other words, by using educational games during lectures or teaching, students will be required to focus on the teaching content in order to successfully complete the tasks in the game, whilst their learning motivation may remain high due to the inclusion of game elements in the learning process.

However, the advantages of using gamification in education does not necessarily mean it would receive overwhelming advocacy, as it had produced some mixed results (Hanus and Fox, 2015). Whitton (2007) even documented that their participants did not find educational games motivating or interesting, elucidating that since individuals normally play games for entertainment purposes, the deployment of gamification in educational environments/settings may not produce the same motivational effect. If individuals have the option of either playing educational or casual games, they are more likely to choose the latter (Karakus et al., 2008), because they may perceive educational games to be dreary (Kinzie and Joseph, 2008). Furthermore, participating in educational games may even have detrimental effects. According to Dominguez et al. (2013), the utilization of education games was associated with a decline in academic performance.

While the fun side of gamification has counterbalancing effect to learning motivation is not yet known, an educational game is fun and/or motivating, and ultimately effective for learning, will highly depend on learners' personal differences and learning preferences. It is therefore essential to investigate factors affecting the effectiveness of educational games to enhance student learning.

\section{When May Educational Games Be Played?}

The effectiveness of educational games is undoubtedly significant to scholars, but it is equally important to consider how to make the best use of these games. Most educational games are played on computers during classes, but not many are played on mobile and tablet devices. This may limit the usage of these educational games outside of traditional classroom. As a result, students may not be able to take the full benefit of these games. It is worth noting that learning and studying can take place outside the classroom, thus the availability of these portable tools could meet the needs of the students. It is believed that an educational game that enables students to "play" and study conveniently and effectively may be more beneficial for students, particularly in this fast-evolving modern society where individuals spend a vast majority of time on their mobile phones. A study conducted by Hanson et al. (2010) found that college students spend approximately 20 hours on their mobile phones per week, for example, when they are traveling and waiting. The high usage of mobile phones may indicate that if educational games are also available on mobile phones, other than on computers, the opportunity to learn outside of the classroom would increase as individuals may use the educational games applications more often due to their convenience. Thus, the educational game which is available on mobile devices was one of the criteria in the current study. 


\section{Introduction of Educational Game: "PaGam0"}

"PaGamO" is an online gamification learning platform for individuals to learn and compete with each other by participating in a game. Individuals are required to answer questions correctly in the game to successfully build, occupy and conquer territories. It is believed that with such a popular and unique method of motivating students to learn, students would be more motivated and entertained in the learning process. In addition, "PaGamO" provides information for teachers to monitor the learning progress of a large group of students, as shown in the statistics of completion rate and percentage-correctness rates.

With the increasing popularity of "PaGamO," the game is now widely used for different purposes, including but not limited to, language learning, license examinations and other professional training. With over 500,000 players and over US $\$ 6$ million being invested into the game (Business Next, 2015), we may wish to understand the factors behind its quick success ever since its start-up, and more prominently, its effectiveness for learning.

One of the advantages of the "PaGamO" is that it can be accessed via computer, mobile phone and tablet applications. Students can not only review their knowledge prior to their academic tests/examinations, they can also use educational games as study tools in their spare time. If these mobile educational games are developed and used appropriately, they may help enhance students' learning motivation and change their perceptions of learning, i.e., learning can be fun and interesting. In this rapidly changing world, traditional education system may not be as effective as before, hence researchers are very eager to explore alternative learning strategies (Minovic et al., 2012b).

Thus, the principal researcher decided to use the educational game, i.e., the "PaGamO," in the current study. For students in the current study, other assessments (such as quizzes and tests) that were conducted in class accounted for a larger proportion of their final grades. The principal researcher decided that the "PaGamO" assessment scores would contribute to only $5 \%$ of the final grade, so students could try this educational game as a study tool and/or as a supplement to the learning materials in the lectures. After the selection of the educational game, the next step was to design the appropriate instructional strategies according to the theory of enhancing students' learning.

\section{Educational Games and Motivation}

In order to let educational game developers understand how to motivate and encourage individuals to use educational games, it is important to first understand the reasons behind the popularity of recreational games. According to the Interactive Software Federation of Europe (2016), individuals from the Great Britain, France, Germany and Spain spent more than 6 hours every week playing video games, and their gaming activity further increased in 2017 (Interactive Software Federation of Europe, 2016, 2017). Those players are believed to play games for enjoyment without any pressure from outside in participation. Precisely, players are attracted to those games while no one else "force" them or encourage them to play. One explanation is that playing games is intrinsically satisfying for them, as players can experience a sense of enjoyment and fun (Malone and Lepper, 1987). For some, they are willing to pay an absurd amount of money to participate in these video games. Scholars from the education sector are very interested in studying the sources of motivation that lead individuals to spend time and money on these entertainments. It would be fascinating to see if educational games, like popular recreational video games, can enhance motivation for learners. As such, the Self-Determination Theory (SDT; Deci and Ryan, 2004), a widely used theory in motivation, is adopted to aid the discussion in this study. It will also be appropriate to use theoretical reasoning to elucidate the sources of motivation to participate in recreational gamification.

\section{Self-Determination Theory}

Motivation is defined as a decisive psychological process that can stimulate human behavior and guide our behavior to specific situations (Reeve et al., 2004). Self-Determination Theory (SDT; Deci and Ryan, 2004) meticulously explains about the sources of motivation in some specific situations, in this context, it is to play educational games. This theory comprises of three different types of motivation, namely "intrinsic motivation," "extrinsic motivation," and "amotivation." "Intrinsic motivation" refers to internal feelings, such as enjoyment, pleasure or interest, which drive the individuals to participate in a particular activity. For example, a game player may play a recreational game because he enjoys it. Conversely, "extrinsic motivation" consists of external rewards or outside pressure that encourage or push individuals to behave in a certain way. For example, a player may play a game because he wants to win a medal. The behavior is merely directed by the external reward rather than intrinsic feelings. It is worth noting that over-reliance on extrinsic rewards can weaken the existing intrinsic motivation because individuals are likely to focus on the extrinsic reward as a source of motivation (Lepper and Henderlong, 2000). Finally, "amotivation" indicates that individuals are not motivated at all to complete a particular activity. In the educational context, individuals may not be psychologically driven to participate in certain educational activities, for example, to play educational games, because they are simply not motivated.

It is believed that the adherence to a particular activity will be longer if we engage with intrinsic motivation (Ryan et al., 1997). Intrinsic motivation can be enhanced when three basic psychological needs are met, namely "autonomy," "competence" and "relatedness." How the three needs are relevant to the current study will be discussed in detail in later part of this paper. It is suggested that when one of them is achieved, it is likely to increase a sense of intrinsic motivation in oneself. If three of the needs are all satisfied, the level of motivation may be further enhanced (Deci and Ryan, 2004). However, it is worth noting that the three basic psychological needs may offset each other and can be an impediment of one or another needs. Specifically, one of the needs can be fulfilled at the expense of the others, or two needs can be met through the same task (Ryan and Deci, 2000). For example, collaboration in a group may yield a sense of relatedness, but at the expense of one's need for autonomy because other group members may not approve certain decisions, therefore freedom can be limited. On the other 
hand, two psychological needs (relatedness and competence) can be satisfied when a group has successfully mastered a particular task together. It is therefore recommended that when teachers are supporting one of the psychological needs, they should be wary of not thwarting the other needs (Van Roy and Zaman, 2017).

\section{Need for Autonomy}

In education, "autonomy" refers to the absence of external pressure to force the learners to act or behave in a certain way during the learning process. Individuals would have freedom of choosing whether or not they will take certain actions, and when those actions are being taken. For example, if individuals can choose when to exercise during the week, instead of having a fixed schedule of running on every Monday, Wednesday, and Friday, they are more likely to enjoy exercising because they would enjoy a sense of autonomy. In the educational context, when students are being put in situation where it is controlling, such as having very strict parents and teachers, the level of autonomous motivation is likely to descend (Rigby and Ryan, 2011). Moderate level of choice and freedom have been found to be fundamental toward autonomous motivation (Deterding, 2015). However, Rigby and Ryan (2011) believed that individuals can still have a sense of autonomy even when only one single option is provided. For example, if students are being instructed to write an essay on a particular topic, and if that topic aligns with their interest or strength, that will allow the students to have a sense of volition.

With regard to the current study, the authors believe that a sense of autonomy was achieved through the freedom of: (1) choosing when to play the game, rather than forcing them to play in class, and (2) choosing whether to use the "PaGamO" as a study tool or not. Although some may argue that students' sense of autonomy may diminish as the "PaGamO" scores would contribute only $5 \%$ to the students' final academic grade, the researchers believe that the small fraction would not negatively affect students' sense of autonomy. On the contrary, this could encourage students to participate in the game, and students could possibly become more intrinsically motivated once they have explored the interesting and motivating side of the game.

\section{Need for Relatedness}

The need for relatedness can be achieved when individuals feel that they belong to a particular group (Deci and Ryan, 2004). When humans have the opportunity to share experiences, the positive feelings will be strengthened and fostered (Rigby and Ryan, 2011). Although students may be involved in school settings where they can become competitive, they all share a common goal-to achieve academic success. If teamwork is encouraged, it would enable students to share their knowledge and experiences, resulting in stronger bonds, higher sense of relatedness and motivation to complete a common task together (Carr and Walton, 2014). The benign competition against other groups would perhaps drive students to improve as a group to fulfill a sense of relatedness and competence.

In the current study, 4-5 students formed a team. The "PaGamO" also allowed students to send messages among themselves to discuss their team tactics and share their academic knowledge. Taking the advantage of using social features, the students were encouraged to work together to complete the "missions" - to facilitate interaction among them and lead to better assessment grades (De-Marcos et al., 2016).

\section{Need for Competence}

The "need for competence" refers to the feeling of being able to successfully master a particular task/activity (Deci and Ryan, 2004). Students who experience a sense of competence are more likely to persist in the face of challenges, and have better academic results than those who are incompetent (Rigby and Ryan, 2011). However, it is not just a matter of making the activities/tasks easy to accomplish, so that students can experience a sense of mastery. Teachers should ensure that the tasks are being set at an "appropriately difficult level" where they are challenging, yet attainable (Peng et al., 2012), as students may feel bored if they can do the task effortlessly, or may become anxious if it is too difficult (Csikszentmohalyi, 1990).

In the current study, with over 50 students in the sample, it is not feasible to ensure that the difficulty of the questions is challenging yet attainable for every student. Therefore, the researchers included a set of easy, medium and hard questions in the "PaGamO" sessions, with a large proportion being at medium level. Students were also encouraged to seek advice from the principal researcher if they would perceive the questions to be too challenging, i.e., tutorial sessions. Thus, students would feel more comfortable and competent when they thoroughly understand the content, and would be able to master the "hard" questions.

\section{Ways to Enhance Intrinsic Motivation}

One of the factors that Malone and Lepper (1987) mentioned to increase intrinsic motivation is curiosity. If learners are curious and have a desire for knowledge, they are more likely to pay more attention to the new information in order to integrate into their existing knowledge. Curiosity is induced when there is a gap between our perceived discrepancies or conflicts from our personal expectations and knowledge (Loewenstein, 1994). As human beings, we are curious about our surroundings and the world in order to make sense of the things that we are not certain and/or could not explain. On the other hand, as Garris et al. (2002) argued, whether an individual is motivated to learn can be determined by the complexity of the information. For example, if the information is considered to be slightly discrepant/easy, the learner may simply disregard the message. On the contrary, if the new information has a high level of discrepancy compared with our existing knowledge, or if the content is too difficult, it may confuse the learner, and he/she may lose motivation or interest to learn the new knowledge. In this sense, it should be taken into consideration when designing the questions for students in educational games. The questions should be set at a level where students can feel challenged, yet attainable.

In addition, many children and adolescents do not participate in outdoor sports or physical activities, but they play computer and video games in their spare time (Mumtaz, 2001), so educators are interested in combining educational content with educational games to enhance students' intrinsic motivation for learning 
(Prensky, 2001). Prensky has provided some suggestions to keep players intrinsically challenged: (1) to ensure that individuals feel challenged, and experience a sense of mystery and control while playing; (2) when designing the game, ensure that the level of difficulty of the game should neither be too easy nor too difficult, otherwise both may affect the player's motivation; (3) the player's score should be provided to the player so that he/she can track the progress while pursuing the goal; and (4) the purpose of playing the game must be relevant and meaningful to the player-gaining specific knowledge from participating in the game should provide a purpose for the learner to be adherent to the game. This study has followed each of the aforementioned guidelines with an aim to enhance intrinsic motivation in learning.

\section{Objective}

This study uses a combination of gamification and traditional learning methods, while implementing the elements of selfdetermination theory to design the instructional strategies to motivate students. The aim is to study whether the use of educational game "PaGamO" could enhance students" learning ability and understand students' perceptions of educational games.

\section{MATERIALS AND METHODS}

\section{Participants}

The participants consisted of 56 college students $(32 \mathrm{men}, 24$ women, Mage $=21$ years, $S D=1.72)$ majoring in physical education and recreation management and taking the motor learning and development course. Each group consisted of 45 students; a total of 12 groups were formed. In addition, a total of five students, who had achieved low, medium, and high scores (score range from 19 to 94 out of 100 points) in the tasks using "PaGamO," had participated in focus-group interviews, further enabling the researchers to collect students' opinions on "PaGamO" in exhaustive detail. According to Morgan (1988), a small focus-group encourages participants to make more contributions.

\section{Procedure}

Since the educational game "PaGamO" was newly introduced to the researchers in this study, a meeting was held with the Senior Project Officer (SPO) of the University's Centre for Holistic Teaching and Learning in order to gain a thorough understanding on how the educational game functions. SPO provided clear instructions and recommendations to ensure that the game could run and be managed smoothly and effectively.

Then, the principal researcher/lecturer of the course designed a list of 100 multiple-choice (MC) questions based on the course materials. Afterward, the researchers checked the quality and the accuracy of the questions and answers. They also discussed the difficulty of the questions and ensured that the questions were comprised of different levels, namely simple, medium, and difficult. After successfully uploading the questions to the "PaGamO" system, the SPO and researchers introduced the game instructions to students in detail. Technical support was also provided to ensure that all students could download and install the "PaGamO" game effectively.

In order to increase the sense of competitiveness while playing the game, 4-5 students formed their own team. A total of 12 teams were eventually formed. Teams and individuals with the highest scores at the end of the study would be awarded. Meanwhile, the principal researcher would send weekly reminder to students to participate in the game. Upon completion of each section, students would receive individual and team scores.

Students played the "PaGamO" game in four sections according to the theme of the module. As the principal researcher decided to encourage and increase the motivation among the students, the latter were informed that 20 of the 100 questions in "PaGamO" would be included in the final examination. In addition, the final "PaGamO" score would contribute 5\% to the students' final grade. Students were given 7-10 days to complete the questions (the length of the completion time depended upon the number of questions in different sections). All tasks of the four sections were required to be completed within 5 weeks. The principal researcher also encouraged students to collaborate with their team-mates and/or search for answers in handouts and textbooks, that aimed to stimulate their critical thinking and make it easier for them to absorb what they have learned.

\section{Data Collection and Analysis}

A mixed-method approach was used to thoroughly assess the effectiveness of "PaGamO." The current study extracted primary data via the use of questionnaires and was supplemented by interview in which feedback and answers were thematically analyzed.

\section{Quantitative Method}

Students' perceptions and opinions of "PaGamO" were evoked immediately after the completion of their final examination through a questionnaire which consisted of two sections. Questions on Section 1 were modified from the questionnaire of Riemer and Schrader (2015) entitled "Students' attitudes, perceptions and intentions to learn with different types of serious games." For example, the question "I would like to use serious games regularly for learning" was changed to "I would like to use 'PaGamO' regularly for learning." The reason for changing the wording was to ensure that students were indicating their level of agreement or disagreement based on the "PaGamO," instead of general educational games. Questions on Section 2 specifically focused on "PaGamO," such as "Would you like the game 'PaGamO' to be played in other courses?" and "What are your motives to play 'PaGamO'?"

\section{Qualitative Method}

To help answer the research question (In what ways the application of the educational game to enhance student learning?), a group of students were subsequently invited as members of a focus-group to elaborate their thoughts on "PaGamO." In the questionnaire, a student strongly agreed to the statement "I would like to use 'PaGamO' regularly for learning." In order to understand the reasons behind this response, the breadth and depth of the information was gathered 
through exhaustive interviews with the students. For example, the students elaborated and insisted, “ $\mathrm{PaGamO}$ ' can help me revise for the final exam for this module". This extensive information enabled researchers to better understand this circumstance.

Prior to the interviews, trust and rapport were built in order that participants would provide truthful and exhaustive data for precise and valid analysis (Hodge et al., 2014). In addition, the researchers also ensured that the questions in the interview guide were open-ended and non-leading (Patton, 2002). Semistructured interviews lasted 30 minutes on average. The audio recording was used to assist the note-taking in order to ensure the accuracy of the latter. After that, the transcript of the interview was translated back to back to confirm accuracy.

Some of the literatures identified by Boyle et al. (2016) have examined the effectiveness of educational games on learning using randomized control trial (RCT) and quasi-experimental design. However, as the students participated in this study were taking a university course, and they were assessed as a whole class, it would not be feasible to allocate them into experimental and control groups. Furthermore, it would be meaningless to conduct a pre-test as our participants would have limited knowledge in the motor development and learning topics.

\section{RESULTS AND DISCUSSION}

\section{Students" "PaGamO" Score and Examination Score}

There were $48.3 \%$ of the students completed a total of four sections of the game, and eight of them scored above 80 points out of 100. The final examination consisted of three parts, namely, MC questions (20\%), fill in the blanks (20\%), and long questions (60\%). A statistical analysis was conducted to examine whether there was relationship between the educational game "PaGamO" score and the final examination score. The quantitative data was supported by qualitative findings received from focus-group interviews.

A simple regression was conducted to examine the relationship between the "PaGamO" ("PaGamO" score) and the MC and final examination scores. Regression analysis indicated that "PaGamO" score was a significant $(p<0.01)$ predictor of $\mathrm{MC}$ score in the final examination. A medium positive correlation $(\beta=0.354)$ was found. The $R^{2}$ suggests that $12.6 \%$ of MC score was explained by "PaGamO" score. For the final examination score, the "PaGamO" score was not a predictor $(p=0.065)$. The $R^{2}$ suggests that only $6.3 \%$ of final examination score was explained by "PaGamO" score. One possible explanation was that the format of the question in "PaGamO" was MC questions, while there were other questions in different formats in the final examination. Therefore, it could be more challenging if students were unable to transfer and apply their knowledge from one format to another while answering the questions. Also, they had never seen the long questions before the final examination, unlike the questions in $\mathrm{MC}$ which primarily were included in the "PaGamO" game.

Some students had a low "PaGamO" score, but had a high MC 20 mark on the final examination were observed. We assumed that students tended to use their existing knowledge to conduct self-tests rather than searching for answers directly using their lecture notes. These assumptions are supported by students in the focus group:

"At the beginning, I don't use notes because I want to see how much I know, but for the questions that I did wrongly, probably when I was wrong twice, I would use the notes in the third time. Because if you get the notes out at the beginning, you won't remember the answer (for the final exam), but when you are wrong, you will know what you have done wrong."-Student A.

"When I played it the first time, I did not revise for it, I based on my memory only and tested myself to see how much I remember. For second time, I did do a bit of revision, because I want to get higher scores."-Student B.

"PaGamO" could be an effective tool for studying and students seemed to have learnt by adopting the "trial and error" strategy to strengthen their memory on the subject. Another reason for scoring the high MC mark was possibly because the students had been informed that $20 \%$ of the questions in "PaGamO" would repeat in the MC section in the final examination.

One of the main purposes for using educational games is to provide an alternative learning option for students, with an aim to help them study more effectively in an entertaining manner. A student said, "I think this app is quite good, because it is a game, it allows me to revise in a relaxing way, unlike how I normally revise which I just try to remember everything" (Student $C$ ). When nearing the end of the semester, with assignment deadlines and examination periods approaching, it could become a stressful period for students. The quote aforementioned suggests that students perhaps can study effectively "in a relaxing way" rather than simply over-loading their memory. The elements of the game could be new, exciting and challenging for students to learn and study. This method was also welcomed by other students from the same class, "I can play education game in this subject, I think it's quite special" (Student D) and "it's better than keep on revising my notes again and again, PaGamO is a more interesting way to revise, so why not use it." (Student $E$ ). Hence, the findings support that the educational game can enhance students to study the course materials and could be effective in learning.

\section{Students' Motives to Play "PaGamO"}

Motives for participating in the "PaGamO" were mainly intrinsic as suggested in the top 10 motives of the list, i.e., (1) fun, (2) self-learning, (3) want to get a higher grade in the final examination, (4) challenging, (5) want to get a higher score in the game, (6) enjoyment, (7) I can choose when to play, (8) self-achievement, (9) want to win, and (10) the game has high relevance to my learning. The findings are consistent with previous research (Dominguez et al., 2013; Sun-Lin and Chiou, 2019) and they support the gamified design to make learning tasks more interesting and fun, thereby attracting students' attention and motivating them to complete the learning tasks. 
In addition, not only were the students driven by both intrinsic and extrinsic motives to play the "PaGamO," there was also the social factor involved. Student A remarked:

"The game is simple and it has ranking, that's why it is competitive, it is fun. It is challenging. . you have to compete with others, so that you have the motivation to play, because you would want to compare with others, if you can see the ranking, the motivation level is higher."

Herodotou et al. (2014) argued that the theory of selfdetermination did not well predict individuals' motivations for playing entertainment games. In their research, they found a weak association between basic psychological needs and game playing. The researchers believe that one of the main factors motivating individuals to play casual games is the social interaction between players, who would cooperate and/or compete with each other. In the current study, the view provided by Student A supports the discovery of Herodotou and the research team, suggesting that social interaction and competitiveness are key to game players' participation in the game.

\section{Students' Perceptions of Educational Games}

In order to study students' cognitive perception and intention to use the "PaGamO," 15 statements on the 7-point Likert scale were listed and utilized for in-depth analysis. The top five statements are: (1) 'In my opinion, the use of 'PaGamO' enables me to better prepare for the final examination" $(M=5.04, S D=1.41)$, (2) "In my opinion, the use of 'PaGamO' enables me to understand learning contents" $(M=4.8, S D=1.19)$, (3) "In my opinion, the use of 'PaGamO' allows me to apply knowledge" $(M=4.75$, $S D=1.08)$, (4) “In my opinion, by using 'PaGamO,' I can learn easily" ( $M=4.67, S D=1.28)$, and (5) "In my opinion, using 'PaGamO' enhances my learning performance" $(M=4.65$, $S D=1.35)$ (see Table 1).

Since "In my opinion, the use of 'PaGamO' enables me to better prepare for the final examination" was the highest ranked statement, it was deemed essential to ensure that further elaboration was heard from the students. When being asked how

TABLE 1 | Students' perceptions and intentions to use the educational game.

\begin{tabular}{|c|c|c|c|}
\hline $\begin{array}{l}\text { Rank } \\
\text { order }\end{array}$ & Statement & $M$ & $S D$ \\
\hline 1 & $\begin{array}{l}\text { In my opinion, the use of PaGamo } \\
\text { enables me to better prepare for the } \\
\text { final examination }\end{array}$ & 5.04 & 1.41 \\
\hline 2 & $\begin{array}{l}\text { In my opinion, the use of PaGamO } \\
\text { enables me to understand learning } \\
\text { contents. }\end{array}$ & 4.80 & 1.19 \\
\hline 3 & $\begin{array}{l}\text { In my opinion, the use of PaGamo } \\
\text { allows me to apply knowledge. }\end{array}$ & 4.75 & 1.08 \\
\hline 4 & $\begin{array}{l}\text { In my opinion, by using PaGamO, I can } \\
\text { learn easily. }\end{array}$ & 4.67 & 1.28 \\
\hline 5 & $\begin{array}{l}\text { In my opinion, using PaGamO } \\
\text { enhances my learning performance. }\end{array}$ & 4.65 & 1.35 \\
\hline
\end{tabular}

"PaGamO" was helpful in their final examination, Student C recalled, 'in 'PaGamO,' when you are wrong, you are more likely to remember it better, and when the questions come up again in the exam, then you won't be wrong again." Similar responses were also heard from Student D, who said, "after answering the questions, I can remember it very well." It was evident that the "trial-and-error" approach had helped students memorize the content successfully who subsequently could apply the knowledge in the final examination.

Furthermore, based on the 15 statements of "Students' attitudes, perceptions and intentions to learn with different types of serious games" questionnaire of Riemer and Schrader (2015), three factors were also examined and the findings are as follows: (1) perceived potential to support performance which includes items on beliefs about whether the game promotes specific learning performance, such as the final examination (range $=8$ $35, M=23.82, S D=5.48$ ); (2) perceived potential to support performance which includes items on beliefs about the overall efficiency and effectiveness of academic performance through the use of games (range $=6-35, M=22.89, S D=6.27$ ); (3) usage intention, address the intention to use or avoid using serious games for learning (range $=5-35, M=19.38, S D=5.38$ ). Moreover, independent $t$-test results of the three factors show that men and women have similar views on "PaGamO."

However, as mentioned earlier, perceptions of whether "PaGamO" is interesting and motivating largely depend on individual differences and learning preferences. As Student E recalled:

"PaGamO" doesn't help that much... after I complete it, I won't actually remember what we have answered. . I don't actually like to use these methods (educational games) to revise. Traditional learning and revision will help me more, it is better to have quizzes in classes than "PaGamO."

Consistent with previous literature by Whitton (2007), and Chen et al. (2019), the citations above suggest that not all students would find educational gamification fun and motivating. Some students may prefer to use traditional learning and teaching methods as a result of, perhaps, its being a habitual behavior. Furthermore, the game design may also affect students' perceptions of "PaGamO."

"PaGamO" is less fun compared to the one I played before, in "PaGamO," you can only upgrade your land or rob other people's lands, but the one that I played before had different subjects, it had some words that come out and you select the right ones, but "PaGamO" only had $A, B, C$, like exams. - Student C.

As such, it is important to ensure that the game design is fun enough to keep students engaged. MC questions may appear too similar to the examination in the current study. Although the researcher is convinced that if $\mathrm{MC}$ questions can mimic the format of the examination, students may prepare better for the examination. However, Student C's view suggests that when educational gamification is too similar to the formats of the examination, it can become demotivating and tedious. Since it 
is not clear which question format is best for students' learning, further research is necessary.

\section{Technological Devices for Playing Educational Games}

In relation to the devices used by students to play "PaGamO," it was reported that 42 students used mobile phones, 12 used tablets and 2 used computers. The use of a mobile phone enabled students to play "PaGamO" conveniently, which could increase the frequency of game participation. Student A and C mentioned, respectively, "I think this game is quite good, because it is portable, you can bring it anywhere (mobile), so when you are free, you can take it out and play the game" and "because it is more convenient, you can simply press the app button, and you can play." The convenience undoubtedly enabled students to learn and/or study more often without having to carry textbooks/lecture materials around. They could simply open the "PaGamO" application on their mobile phones and immediately start playing and studying.

Likewise, despite not many students used computers to play "PaGamO," one student pointed out its convenience, as student B recalled, "When I open the 'PaGamO' link, I don't normally close it, so when I turn on my computer, I can play the game." The choice of devices used to play "PaGamO" would depend upon personal preferences and the availability of devices. This game also allowed students to have freedom to decide when to play and on what devices to play.

\section{Average Time Spent on "PaGamO" for Each Session}

For each "PaGamO" session, 62.5\% of students used "PaGamO" for less than an hour, while 32.7 and $1.8 \%$ of them spent between 1 hours and within 2 hours, and between 2 hours and within 3 hours, respectively. Studying can be mentally demanding and dull for students as they would have to maintain high concentration during the process. One of the purposes of using "PaGamO" was to enable students to study while "playing" and make it more interesting rather than boring. Notwithstanding the time spent on "PaGamO" was not considerably long, "PaGamO" can be considered effective and successful in helping students to prepare for their final examination as the average score for $\mathrm{MC}$ was 16.12 out of 20 points $(S D=2.99)$. When asked about how much time was spent on "PaGamO," Student E revealed that "around 35-40 min, including time spent on viewing notes." It was sufficient for students to study the key points of the subject within an hour.

\section{Other Key Factors Extracted From Questionnaire Data and Interviews}

There were $48.3 \%$ of students completed all four sessions of the game. While the researchers have been studying the effectiveness of the game and students responses, adding to the fact that educational games have just been developed and are still in the early stage in higher education, the present full-participation rate is acceptable.

However, the researchers understood that there were still areas for further enhancement in educational game, such as the number of the questions (a few respondents reported that 100 questions were insufficient) and the format of the question (students recommended different formats to be used along with the MC questions). Additionally, when asked if students would like to play "PaGamO" in other modules, 56\% said they would welcome this idea, while some mentioned that it would be difficult to play "PaGamO" in two or more subjects simultaneously.

In summary, by using gamification as a tool for learning and studying, students did find "PaGamO" effective for their learning experience. The motives of using "PaGamO" came from both intrinsic and extrinsic motives, with more students toping to play "PaGamO" for "Fun." In addition, the use of mobile phones to play "PaGamO" was indeed more popular than using computers and tablet devices because of its convenience. Furthermore, the combination of gamification and traditional learning methods could enhance students learning.

\section{Recommendations for Further Research}

The sample size of the present study was 56 . As mentioned earlier, this is an exploratory study which aims to examine the application of educational game on students' learning. Considering the cost of the game accounts, administration time, and manpower, it would not have been appropriate to widely utilize the educational game before assessing its suitability and effectiveness. As the results of the current research are positive, it is expected that a larger sample size can be used in future to investigate students' attitudes, perceptions and willingness to learn.

During the research period, only three courses (computer sciences, music, and physical education) had utilized this educational game as a supplementary tool to integrate into the traditional teaching method in the University. At the same time, different course instructors adopted different approaches to design the questions and the degree of involvement of students was varied. It is suggested that, in future, course instructors of different subjects should discuss and standardize the research procedures, so as to conduct comparative study to facilitate the investigation of the effectiveness of educational games on student learning and students' perceptions on educational games for different disciplines.

Due to the experimental nature of the study, only MC questions were used in the educational game. To avoid the limitation, in future, more formats of questions could be explored, such as using fill-in-the-blanks and short questions. This strategy can help students learn by mimicking real test scenarios under less stressful situations.

It is also feasible that, as researchers in this study introduced the use of educational game prior to students' final examination, future studies may explore the long-term effects of gamification on students' knowledge retention and the applicability of information in other contexts.

\section{CONCLUSION}

The results of the current study show that the combination of gamification and traditional learning methods can 
enhance students' learning motivation and learning effects. The higher the "PaGamO" score, the higher the MC score is observed. Student learning is also influenced by the content of the game, the format of the question, the instructional strategies, and the motivation for participation. In addition, due to its convenience, playing educational game on mobile devices is more popular than using computers and tablet devices. In conclusion, with the development of educational technology, educational games are becoming more and more popular, and further research is therefore recommended.

\section{DATA AVAILABILITY STATEMENT}

The raw data supporting the conclusions of this article will be made available by the authors, without undue reservation.

\section{ETHICS STATEMENT}

Ethical review and approval was not required for the study on human participants in accordance with the local legislation and institutional requirements. Written informed consent for

\section{REFERENCES}

Adachi, P. J., and Willoughby, T. (2013). More than just fun and games: The longitudinal relationships between strategic video games, self-reported problem-solving skills, and academic grades. J. Youth Adolescence 42, 10411052. doi: 10.1007/s10964-013-9913-9

Al-Azawi, R., Al-Fatma, F., and Al-Blushi, M. (2016). Educational gamification vs. game based learning: Comparative study. Int. J. Innovat. Manag. Technol. 7, 132-136. doi: 10.18178/ijimt.2016.7.4.659

Boyle, E. A., Hainey, T., Connolly, T. M., Gray, G., Earp, J., Ott, M., et al. (2016). An update to the systematic literature review of empirical evidence of the impacts and outcomes of computer games and serious games. Comput. Educ. 94, 178-192. doi: 10.1016/j.compedu.2015.11.003

Business Next (2015). Revolving education with science and technology, National Taiwan University team "PaGamO" received a USD 6 million investment from Hong Hai. Available online at: https://www.bnext.com.tw/article/36116/BN2015-04-29-134339-34. (accessed June 26, 2019).

Calderón, A., and Ruiz, M. (2015). A systematic literature review on serious games evaluation: An application to software project management. Comput. Educ. 87, 396-422. doi: 10.1016/j.compedu.2015.07.011

Calliari, D. (1991). Using games to make learning fun. Rehabilitation Nursing J. 16, 154-155. doi: 10.1002/j.2048-7940.1991.tb01202.x

Carr, P. B., and Walton, G. M. (2014). Cues of working together fuel intrinsic motivation. J. Exp. Soc. Psychol. 53, 169-184. doi: 10.1016/j.jesp.2014.03.015

Chen, S. W., Yang, C. H., Huang, K. S., and Fu, S. L. (2019). Digital games for learning energy conservation: A study of impacts on motivation, attention, and learning outcomes. Innovat.Educ. Teach. Int. 56, 66-76. doi: 10.1080/14703297. 2017.1348960

Csikszentmohalyi, M. (1990). Flow: The psychology of optimal experience. New York,NY: Harper \& Row.

Deci, E. L., and Ryan, R. M. (eds) (2004). Handbook of self-determination research. Rochester: University Rochester Press.

De-Marcos, L., Garcia-Lopez, E., and Garcia-Cabot, A. (2016). On the effectiveness of game-like and social approaches in learning: Comparing educational gaming, gamification \& social networking. Comput. Educ. 95, 99-113. doi: 10.1016/j. compedu.2015.12.008 participation was not required for this study in accordance with the national legislation and the institutional requirements.

\section{AUTHOR CONTRIBUTIONS}

SC: design of the study, data collection, data analysis, and writing of the manuscript. KN: data collection, assist in data analysis, and draft of the manuscript. Both authors contributed to the article and approved the submitted version.

\section{FUNDING}

This research was funded by the University Grants Committee of Hong Kong, under the Funding Scheme for Teaching and Learning Related Projects (2016-2019, Triennium; HKBU4/T\&L/16-19).

\section{ACKNOWLEDGMENTS}

We would like to thank our colleagues at the Centre for Holistic Teaching and Learning of Hong Kong Baptist University for supporting this study.

Deterding, S. (2015). The lens of intrinsic skill atoms: A method for gameful design. Hum. Comput. Interact. 30, 294-335. doi: 10.1080/07370024.2014.99 3471

Dominguez, A., Saenz-De-Navarrete, J., De-Marcos, L., Fernandez-Sanz, L., Pages, C., and Martinez-Herraiz, J. J. (2013). Gamifying learning experiences: Practical implications and outcomes. Comput. Educ. 63, 380-392. doi: 10.1016/ j.compedu.2012.12.020

Fitzgerald, K. (1997). "Instructional methods: Selection, use, and evaluation," in Nurse as educator: Principles of teaching and learning, ed. S. Bastable (Burlington, MA: Jones and Bartlett Learning), 261-286.

Garris, R., Ahlers, R., and Driskell, J. E. (2002). Games, motivation, and learning: A research and practice model. Simulat. Gaming 33, 441-467. doi: 10.1177/ 1046878102238607

Gros, B. (2007). Digital games in education: The design of games-based learning environments. J. Res. Technol. Educ. 40, 23-38. doi: 10.1016/j.compedu.2013. 06.005

Hanson, T. L., Drumheller, K., Mallard, J., McKee, C., and Schlegel, P. (2010). Cell phones, text messaging, and Facebook: Competing time demands of today's college students. College Teach. 59, 23-30. doi: 10.1080/87567555.2010. 489078

Hanus, M. D., and Fox, J. (2015). Assessing the effects of gamification in the classroom: A longitudinal study on intrinsic motivation, social comparison, satisfaction, effort, and academic performance. Comput. Educ. 80, 152-161. doi: 10.1016/j.compedu.2014.08.019

Herodotou, C., Kambouri, M., and Winters, N. (2014). Dispelling the myth of the socio-emotionally dissatisfied gamer. Comput. Hum. Behav. 32, 23-31. doi: 10.1016/j.chb.2013.10.054

Hodge, K., Henry, G., and Smith, W. (2014). A case study of excellence in elite sport: Motivational climate in a world champion team. Sport Psychol. 28, 60-74. doi: $10.1123 /$ tsp.2013-0037

Interactive Software Federation of Europe (2016). Game track digest Q4 2016. Available online at: https://www.isfe.eu/publication/gametrack-digestq4-2016/ (accessed June 26, 2019).

Interactive Software Federation of Europe (2017). Game track digest Q4 2017. Available online at: https://www.isfe.eu/wp-content/uploads/2019/01/ gametrack_european_summary_data_2017_q4.pdf (accessed June 26, 2019). 
Karakus, T., Inal, Y., and Cagiltay, K. (2008). A descriptive study of Turkish high school students' game-playing characteristics and their considerations concerning the effects of games. Comput. Hum. Behav. 24, 2520-2529. doi: 10.1016/j.chb.2008.03.011

Kinzie, M. B., and Joseph, D. R. (2008). Gender differences in game activity preferences of middle school children: implications for educational game design. Educ. Technol. Res. Dev. 56, 643-663. doi: 10.1007/s11423-007-9076-z

Lepper, M. R., and Henderlong, J. (2000). "Turning 'play' into 'work' and 'work' into 'play': 25 years of research on intrinsic versus extrinsic motivation," in Intrinsic and extrinsic motivation, eds C. Sansone and J. M. Harackiewicz (Cambridge,MA: Academic Press), 257-307. doi: 10.1016/b978-012619070-0/ 50032-5

Liao, C. C., Chen, Z. H., Cheng, H. N., Chen, F. C., and Chan, T. W. (2011). My-Mini-Pet: A handheld pet-nurturing game to engage students in arithmetic practices. J. Comput. Assisted Learn. 27, 76-89. doi: 10.1111/j.1365-2729.2010. 00367.x

Loewenstein, G. (1994). The psychology of curiosity: A review and reinterpretation. Psychol. Bull. 116, 75-98. doi: 10.1037/0033-2909.116.1.75

Malone, T., and Lepper, M. (1987). "Making learning fun: A taxonomy of intrinsic motivations of learning," in Aptitude, learning and instruction: Vol 3: Cognitive and affective process analyses, eds R. E. Snow and M. J. Farr (Lawrence: Erlbaum Associates), 223-253.

Minovic, M., Milovanovic, M., Kovacevic, I., Minovic, J., and Starcevic, D. (2012b). "Motivational and cognitive aspects of applying educational games as a learning tool," in Handbook of Research on Serious Games as Educational, Business and Research Tools, ed. M. M. Cruz-Cunha (Pennsylvania: IGI Global), 892-917. doi: 10.4018/978-1-4666-0149-9.ch046

Minovic, M., Štavljanin, V., and Milovanovic, M. (2012a). Educational games and IT professionals: Perspectives from the field. Int. J. Hum. Capital Inform. Technol. Profess. 3, 25-38. doi: 10.4018/jhcitp.2012100103

Morgan, D. L. (1988). Focus groups as qualitative research. Newbury Park, CA: Sage.

Mumtaz, S. (2001). Children's enjoyment and perception of computer use in the home and the school. Comput. Educ. 36, 347-362. doi: 10.1016/S0360-1315(01) 00023-9

Patton, M. Q. (2002). Qualitative Research \& Evaluation Methods, 3rd Edn. Thousand Oaks: Sage Publications, Inc.

Peng, W., Lin, J. H., Pfeiffer, K. A., and Winn, B. (2012). Need satisfaction supportive game features as motivational determinants: An experimental study of a self-determination theory guided exergame. Media Psychol. 15, 175-196. doi: 10.1080/15213269.2012.673850

Prensky, M. (2001). Digital Game-Based Learning. New York, NY: McGraw-Hill.

Prensky, M. (2003). Digital game-based learning. ACM Comput. Entertain. 1, 21-24. doi: 10.1145/950566.950596

Reeve, J., Deci, E. L., and Ryan, R. M. (2004). "Self-determination theory: A dialectical framework for understanding socio-cultural influences on student motivation," in Big theories revisited, eds D. M. Mclnerney and S. Van Etten (Charlotte: Information Age Press), 31-60.
Riemer, V., and Schrader, C. (2015). Learning with quizzes, simulations, and adventures: Students' attitudes, perceptions and intentions to learn with different types of serious games. Comput. Educ. 88, 160-168. doi: 10.1016/j. compedu.2015.05.003

Rigby, S., and Ryan, R. M. (2011). Glued to games: How video games draw us in and hold us spellbound. Westport: Praeger.

Robson, K., Plangger, K., Kietzmann, J. H., McCarthy, I., and Pitt, L. (2016). Game on: Engaging customers and employees through gamification. Business Horizons 59, 29-36. doi: 10.1016/j.bushor.2015.08.002

Rondon, S., Sassi, F. C., Furquim, and de Andrade, C. R. (2013). Computer game-based and traditional learning method: A comparison regarding students' knowledge retention. BMC Med. Educ. 13:30. doi: 10.1186/1472-6920-13-30

Ryan, R. M., and Deci, E. L. (2000). The darker and brighter sides of human existence: Basic psychological needs as a unifying concept. Psychol. Inquiry 11, 319-338. doi: 10.1207/S15327965PLI1104_03

Ryan, R. M., Frederick, C. M., Lepes, D. D., Rubio, N. N., and Sheldon, K. M. (1997). Intrinsic motivation and exercise participation. Int. J. Sport Psychol. 28, 335-354.

Sun-Lin, H. Z., and Chiou, G. F. (2019). Effects of gamified comparison on sixth graders' algebra word problem solving and learning attitude. Educ. Technol. Soc. $22,120-130$.

Van Roy, R., and Zaman, B. (2017). "Why gamification fails in education and how to make it successful: introducing nine gamification heuristics based on selfdetermination theory," in Serious games and edutainment applications, eds M. $\mathrm{Ma}$ and A. Oikonomou (London: Springer), 485-509. doi: 10.1007/978-3-31951645-5_22

Vernon, D. T., and Blake, R. L. (1993). Does problem-based learning work? A meta-analysis of evaluative research. Academic Med. 68, 550-563. doi: 10.1097/ 00001888-199307000-00015

Whitton, N. (2007). "Motivation and computer game based learning," in Proceedings of the Australian Society for Computers in Learning in Tertiary Education, (Singapore), 1063-1067.

Wickens, C. D. (1974). Temporal limits of human information processing: A developmental study. Psychol. Bull. 81, 739-755. doi: 10.1037/h0037250

Zapalska, A., Brozik, D., and Rudd, D. (2012). Development of active learning with simulations and games. US-China Educ. Rev. 2, 164-169.

Conflict of Interest: The authors declare that the research was conducted in the absence of any commercial or financial relationships that could be construed as a potential conflict of interest.

Copyright $\odot 2021$ Cheung and Ng. This is an open-access article distributed under the terms of the Creative Commons Attribution License (CC BY). The use, distribution or reproduction in other forums is permitted, provided the original author(s) and the copyright owner(s) are credited and that the original publication in this journal is cited, in accordance with accepted academic practice. No use, distribution or reproduction is permitted which does not comply with these terms. 